\title{
Supersonic jet epitaxy of gallium nitride using triethylgallium and ammonia
}

\author{
Arthur J. McGinnis, Darren Thomson, Andrew Banks, Edward Preble, \\ and Robert F. Davis \\ Department of Materials Science and Engineering, North Carolina State University, Raleigh, \\ North Carolina 27695-7906 \\ H. Henry Lamb ${ }^{a)}$ \\ Department of Chemical Engineering, North Carolina State University, Raleigh, North Carolina 27695-7905
}

(Received 7 May 2002; accepted 4 November 2002; published 20 December 2002)

Gallium nitride ( $\mathrm{GaN}$ ) films were grown on $\mathrm{GaN}(0001) / \mathrm{AlN} / 6 \mathrm{H}-\mathrm{SiC}$ composite substrates at 700 $780^{\circ} \mathrm{C}$ by supersonic jet epitaxy using triethylgallium (TEG) and $\mathrm{NH}_{3}$. TEG was seeded in $\mathrm{He}$ and $\mathrm{N}_{2}$ supersonic free jets to obtain kinetic energies of $\sim 2.1$ and $\sim 0.5 \mathrm{eV}$, respectively, and $\mathrm{NH}_{3}$ was supplied from a variable leak valve. Higher TEG beam intensities (by about a factor of 5) were obtained by seeding in He. In situ reflection high-energy electron diffraction indicated a transition from three-dimensional to two-dimensional (2D) growth between 730 and $750{ }^{\circ} \mathrm{C}$ for films grown using TEG seeded in $\mathrm{He}$ and a constant $\mathrm{NH}_{3}$ /TEG flux ratio. Ex situ atomic force microscopy of films grown at 730 and $750{ }^{\circ} \mathrm{C}$ revealed smooth surfaces comprised of quasi-2D islands with irregular perimeters. Cross-sectional transmission electron microscopy evidenced that the film grown at $750{ }^{\circ} \mathrm{C}$ was homoepitaxial $\alpha$-GaN with a high density of planar lattice defects. Secondary ion mass spectrometry detected high residual carbon concentrations in the films. The GaN growth rate at $750{ }^{\circ} \mathrm{C}$ was found to depend on TEG flux and $\mathrm{NH}_{3}$ pressure in a manner consistent with Langmuir-Hinshelwood kinetics. Films grown under $\mathrm{NH}_{3}$-rich conditions were faceted and microscopically rough, whereas nonfaceted, basal-plane growth was observed under Ga-rich conditions. The first-order dependence of growth rate on TEG flux under $\mathrm{NH}_{3}$-rich conditions was used to estimate $\mathrm{Ga}$ incorporation efficiencies for high- and low-energy TEG beams. The Ga incorporation efficiency is lower for high-energy TEG beams, consistent with a decrease in the sticking coefficient for dissociative chemisorption. (C) 2003 American Vacuum Society.

[DOI: $10.1116 / 1.1532736$ ]

\section{INTRODUCTION}

Metal-organic chemical vapor deposition (MOCVD) is the primary technique used to grow GaN thin films for optoelectronics applications. ${ }^{1-7}$ Molecular beam epitaxy (MBE) has potential advantages for $\mathrm{GaN}$ growth that include lower growth temperatures, precise control of layer thickness, and in situ doping. In chemical beam epitaxy (CBE), a group III metal-organic compound and a group V hydride are used to grow III-V semiconductor films in a highvacuum environment. ${ }^{8}$ Typically, the growth precursors are transported to the surface via effusive molecular beams in which the kinetic energy of the molecules is fixed by the source temperature. Only a few studies have explored CBE growth of group III nitride materials. ${ }^{9-12}$ Triethylgallium (TEG) and $\mathrm{NH}_{3}$ have been used for GaN growth. The substrate temperature was found to exert a profound influence on GaN film quality as measured by $\mathrm{x}$-ray diffraction. Previous investigators have reported that the optimum temperature for GaN CBE is approximately $800^{\circ} \mathrm{C} \cdot{ }^{11,12}$ Shen et al. also observed that the quality of $\mathrm{GaN}$ films deposited on sapphire was improved by increasing the $\mathrm{NH}_{3}$ flux. ${ }^{12}$ Moreover, better crystalline quality was obtained for $\mathrm{GaN}$ films deposited on $6 \mathrm{H}-\mathrm{SiC}(0001)$ than on sapphire(0001).

\footnotetext{
a) Author to whom correspondence should be addressed; electronic mail: lamb@eos.ncsu.edu
}

Supersonic jet epitaxy (SJE) is a novel growth technique that employs seeded supersonic free jets to impart hyperthermal kinetic energy $(1-10 \mathrm{eV})$ to precursor molecules. ${ }^{13} \mathrm{Hy}-$ perthermal kinetic energies are achieved by seeding a heavy molecule (e.g., $\mathrm{Si}_{2} \mathrm{H}_{6}$ ) in a lighter gas (e.g., $\mathrm{He}$ ) and expanding the gas mixture through a pinhole orifice into high vacuum. Increasing the kinetic energy of impinging molecules will increase the sticking coefficient for dissociative chemisorption if the process is direct and activated (i.e., it does not involve an adsorbed precursor). Direct dissociative chemisorption has been demonstrated for group IV compounds on metal and semiconductor surfaces [e.g., $\mathrm{CH}_{4}$ on $\mathrm{Ni}(111)^{14}$ and $\mathrm{Si}_{2} \mathrm{H}_{6}$ and $\mathrm{SiH}_{4}$ on $\mathrm{Si}(100)$ and $\mathrm{Si}(111)^{15}$ ]. Imparting hyperthermal kinetic energy to $\mathrm{Si}_{2} \mathrm{H}_{6}$ enhances its dissociative chemisorption probability on $\mathrm{Si}(100),{ }^{15}$ and this enhancement translates directly into higher $\mathrm{Si}$ epitaxial growth rates under low hydrogen coverage conditions. ${ }^{16,17}$ Recently, SJE has been employed to grow $\mathrm{SiC}^{18}$ and IIInitride semiconductor ${ }^{19,20}$ films with the objective of lowering the substrate temperature for epitaxial growth. Lowtemperature epitaxial growth of $\mathrm{SiC}$ films on $\mathrm{Si}$ was achieved using a seeded supersonic jet of methylsilane in $\mathrm{H}_{2} \cdot{ }^{18}$ Methylsilane has also been shown to undergo direct dissociative chemisorption on $\beta$-SiC $(100) .{ }^{15}$ Brown et al. used triethylaluminum (TEA) and $\mathrm{NH}_{3}$ for SJE of AlN and reported that imparting hyperthermal kinetic energy to TEA by seeding in 
$\mathrm{H}_{2}$ or $\mathrm{He}$ increased the growth rate markedly. ${ }^{20}$ Consequently, Brown et al. inferred an activation barrier for direct dissociative chemisorption of TEA on AlN that was surmounted via the hyperthermal kinetic energy of the impinging molecules. In contrast, molecular beam scattering measurements have shown that dissociative chemisorption of group III metal-organic compounds, such as TEA, on semiconductor surfaces is unactivated and typically occurs via a precursor-mediated reaction channel. ${ }^{21}$ Moreover, if a precursor-mediated dissociative chemisorption channel is operative, the sticking probability should decrease with increasing kinetic energy of the impinging gas molecule.

In this work, homoepitaxial GaN films were grown by $\mathrm{SJE}$ on $\mathrm{GaN}(0001) / \mathrm{AlN} / 6 \mathrm{H}-\mathrm{SiC}$ composite substrates at 700-780 ${ }^{\circ} \mathrm{C}$ using TEG- seeded supersonic molecular beams and $\mathrm{NH}_{3}$ from a variable leak valve. High $(\sim 2.1 \mathrm{eV})$ and low $(\sim 0.5 \mathrm{eV})$ kinetic energy TEG beams were formed by seeding TEG in $\mathrm{He}$ and $\mathrm{N}_{2}$, respectively. The resultant films were characterized by scanning electron microscopy (SEM), secondary ion mass spectrometry (SIMS), atomic force microscopy (AFM), and cross-sectional transmission electron microscopy (TEM). Flux measurements using a quadrupole mass spectrometer (QMS) were used to establish the relative TEG beam intensities obtained by seeding in $\mathrm{He}$ and $\mathrm{N}_{2}$ supersonic free jets. GaN growth rates were measured as a function of TEG flux at $750{ }^{\circ} \mathrm{C}$ under $\mathrm{NH}_{3}$-rich conditions and used to determine $\mathrm{Ga}$ incorporation efficiencies for lowand high-energy beams.

\section{EXPERIMENT}

\section{A. Apparatus}

The custom-fabricated SJE chamber (low $10^{-9}$ Torr base pressure) is equipped with a QMS (UTI 100C), a $10 \mathrm{keV}$ reflection high-energy electron diffraction (RHEED) gun, and dual doubly differentially pumped supersonic molecular beam sources. $^{22}$ The SJE chamber is connected via a cryopumped transfer line (low $10^{-9}$ Torr base pressure) to a load lock. TEG $\left[\left(\mathrm{C}_{2} \mathrm{H}_{5}\right)_{3} \mathrm{Ga}\right]$ was supplied from a commercial bubbler (Epichem, electronic grade) that was immersed in a temperature-controlled water/ethylene glycol bath. The diluent (carrier) gas $\left(\mathrm{He}\right.$ or $\left.\mathrm{N}_{2}\right)$ is split into two streams: the first stream is regulated by a $50 \mathrm{sccm}$ mass flow controller (MKS) and passes through the TEG bubbler, and the second is regulated by a $500 \mathrm{sccm}$ mass flow controller and bypasses the bubbler. The two streams are recombined and mixed before entering the TEG nozzle. The TEG delivery lines are kept isolated from air and are wrapped with heating tape and baked periodically. A capacitance manometer (MKS Baratron) is used to measure the pressure in TEG bubbler, and a second is used to measure the nozzle pressure. The TEG flow rate can be adjusted by varying the TEG bubbler temperature and the carrier gas flow rate into the TEG bubbler. The TEG mole fraction can be fine-tuned by varying the flow rate through the bypass line. The TEG nozzle was fabricated from stainless steel and has a $50 \mu \mathrm{m}$ laser-drilled Pt orifice. A conical skimmer with a $1 \mathrm{~mm}$ aperture and a $20 \mathrm{~mm}$ base
(Beam Dynamics) is used to form the supersonic molecular beam. A $5 \times 5 \mathrm{~mm}^{2}$ beam-defining aperture separates the SJE chamber from the second differential pumping stage. The molecular beam is incident on the substrate at an angle of $6^{\circ}$ with respect to the surface normal, and the deposition area on the substrate is $15 \times 15 \mathrm{~mm}^{2}$. The QMS was used to measure relative TEG beam intensities, as described previously for $\mathrm{NH}_{3} \cdot{ }^{22}$ The TEG molecules are thermalized by scattering in the deposition chamber before detection.

\section{B. Film growth and characterization}

The substrates were 1.5 - $\mu$ m-thick $\mathrm{GaN}(0001)$ films grown by MOCVD on on-axis $6 \mathrm{H}-\mathrm{SiC}$ using a $0.1 \mu \mathrm{m}$ AlN buffer layer. The MOCVD-grown GaN surface was atomically smooth with a roughness of $0.17 \mathrm{~nm} \mathrm{rms}\left(1 \times 1 \mu \mathrm{m}^{2}\right.$ image size $){ }^{23}$ Substrates $\left(1 \times 1 \mathrm{~cm}^{2}\right)$ were metallized with tungsten on the backside ( $\mathrm{SiC}$ face) to absorb radiation from the pyrolytic boron nitride-coated graphite heater. The GaN substrate temperature was measured using a calibrated infrared optical pyrometer.

Ex situ substrate cleaning was effected by ultrasonic degreasing in trichloroethylene for $20 \mathrm{~min}$. In situ cleaning of the GaN substrates was accomplished by annealing in $\mathrm{NH}_{3}$ $\left(1.5 \times 10^{-5}\right.$ Torr) at $800{ }^{\circ} \mathrm{C}$ for $30 \mathrm{~min}$. After in situ cleaning, the substrate temperature was adjusted to the desired growth conditions. The $\mathrm{NH}_{3}$ background pressure during growth was established by adjusting a variable leak valve (Varian). RHEED patterns were recorded before and after growth using a charge-coupled-device (CCD) camera and software from kSpace Associates.

SEM images of the films were obtained using a JEOL 6400FE SEM with a $5 \mathrm{kV}$ cold field emission electron gun. TEM images were obtained using a Topcon EM-002B with a point-to-point resolution of $0.2 \mathrm{~nm}$. AFM measurements were made using a Digital Instruments Dimension ${ }^{\mathrm{TM}} 3000$ scanning probe microscope (SPM) having AFM and scanning tunneling microscopy (STM) capabilities; tapping mode was chosen for AFM measurements. SIMS depth profiles were measured on a Cameca IMS instrument at a mass resolution of 20000 using a $\mathrm{Cs}^{+}$sputtering source. Crosssectional SEM images of the GaN films were used to determine the film thickness and, hence, the growth rate. It was possible to differentiate GaN films grown by SJE using TEG and the GaN substrate by compositional contrast ( $Z$ contrast) produced by backscattered electrons in the secondary electron image.

\section{Estimating the TEG kinetic energy}

The average kinetic energy achieved by species $i$ in an ideal free jet expansion of a binary gas mixture (assuming zero velocity slip) is given by the following expression:

$$
E_{\text {ideal }}=\frac{W_{i}}{\bar{W}} \bar{C}_{p} T_{0},
$$

where $\bar{C}_{p}$ is the average heat capacity at constant pressure, $\bar{W}$ the average molecular weight of the mixture, $W_{i}$ the mo- 


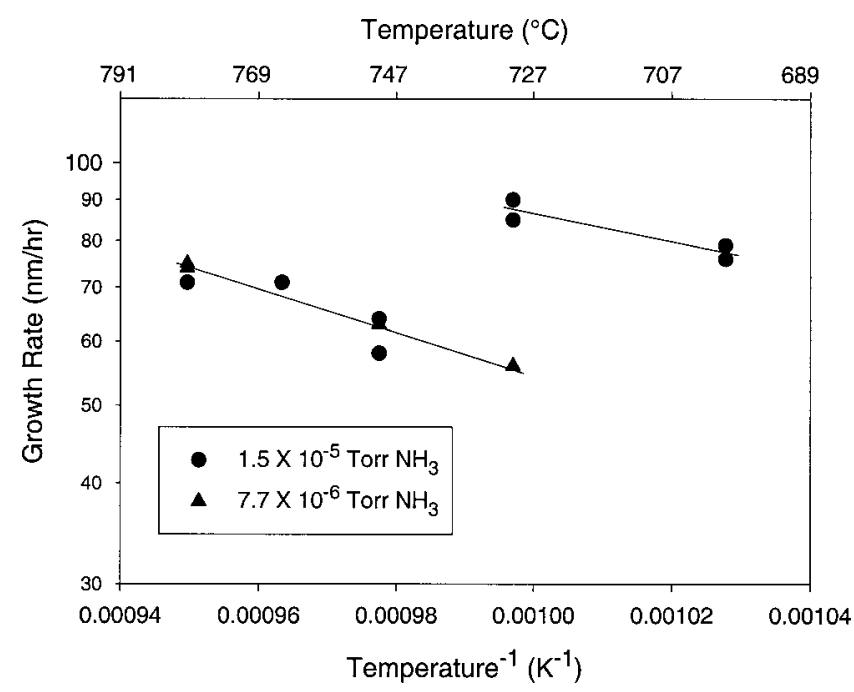

FIG. 1. Growth rate vs reciprocal temperature for homoepitaxial GaN films grown by SJE using $0.55 \mathrm{sccm}$ TEG seeded in $\mathrm{He}$. $\mathrm{NH}_{3}$ pressures during growth are indicated in the legend.

lecular weight of species $i$, and $T_{0}$ the nozzle temperature. ${ }^{24}$ Assuming that $\bar{C}_{p}$ is approximately the heat capacity of the diluent gas, the average kinetic energies of TEG molecules seeded at $1 \%$ in supersonic beams of $\mathrm{He}$ and $\mathrm{N}_{2}$ are 1.8 and $0.48 \mathrm{eV}$, respectively. Differences between the mean velocities of the individual species (velocity slip) can be substantial when a large molecule, such as TEG, is seeded in He; nonetheless, the average kinetic energy of TEG molecules seeded in a He supersonic beam will be significantly higher than that of TEG molecules seeded in $\mathrm{N}_{2}$.

\section{RESULTS AND DISCUSSION}

The GaN substrate initially gave a streaky $1 \times 1$ RHEED pattern indicative of a smooth surface without a thick native oxide layer. Subsequent in situ annealing at $800{ }^{\circ} \mathrm{C}$ under an $\mathrm{NH}_{3}$ pressure of $1.5 \times 10^{-5}$ Torr reduced surface oxygen and carbon contamination to background levels (as evidenced by $\mathrm{x}$-ray photoelectron spectroscopy) and produced a starting growth surface exhibiting a streaky $1 \times 3$ RHEED pattern. ${ }^{23}$ The surface roughness increased after annealing from 0.17 to $0.28 \mathrm{~nm} \mathrm{rms}$, as indicated by analysis of $1 \times 1 \mu \mathrm{m}^{2}$ AFM images. $\mathrm{GaN}$ films were grown at substrate temperatures of $700-780{ }^{\circ} \mathrm{C}$ using $\mathrm{NH}_{3}$ from a variable leak valve and a high-energy beam of TEG seeded in $\mathrm{He}$. $\mathrm{NH}_{3}$ pressures of $1.5 \times 10^{-5}$ and $7.7 \times 10^{-6}$ Torr and a TEG flow rate of 0.55 sccm were used. An Arrhenius plot of the $\mathrm{GaN}$ growth rates is shown in Fig. 1. There appear to be two growth regimes that are characterized by different $\mathrm{NH}_{3}$ reaction orders and slightly different apparent activation energies. The transition between the two regimes occurs between 730 and $750{ }^{\circ} \mathrm{C}$ at an $\mathrm{NH}_{3}$ pressure of $1.5 \times 10^{-5}$ Torr; a $\sim 30 \%$ decrease in growth rate is observed on increasing the substrate temperature from 730 to $750{ }^{\circ} \mathrm{C}$. The growth rate is nearly independent of $\mathrm{NH}_{3}$ pressure for substrate temperatures greater than or equal to $750{ }^{\circ} \mathrm{C}$; however, the growth rate is increased markedly by increasing the $\mathrm{NH}_{3}$ pressure from $7.7 \times 10^{-6}$ to

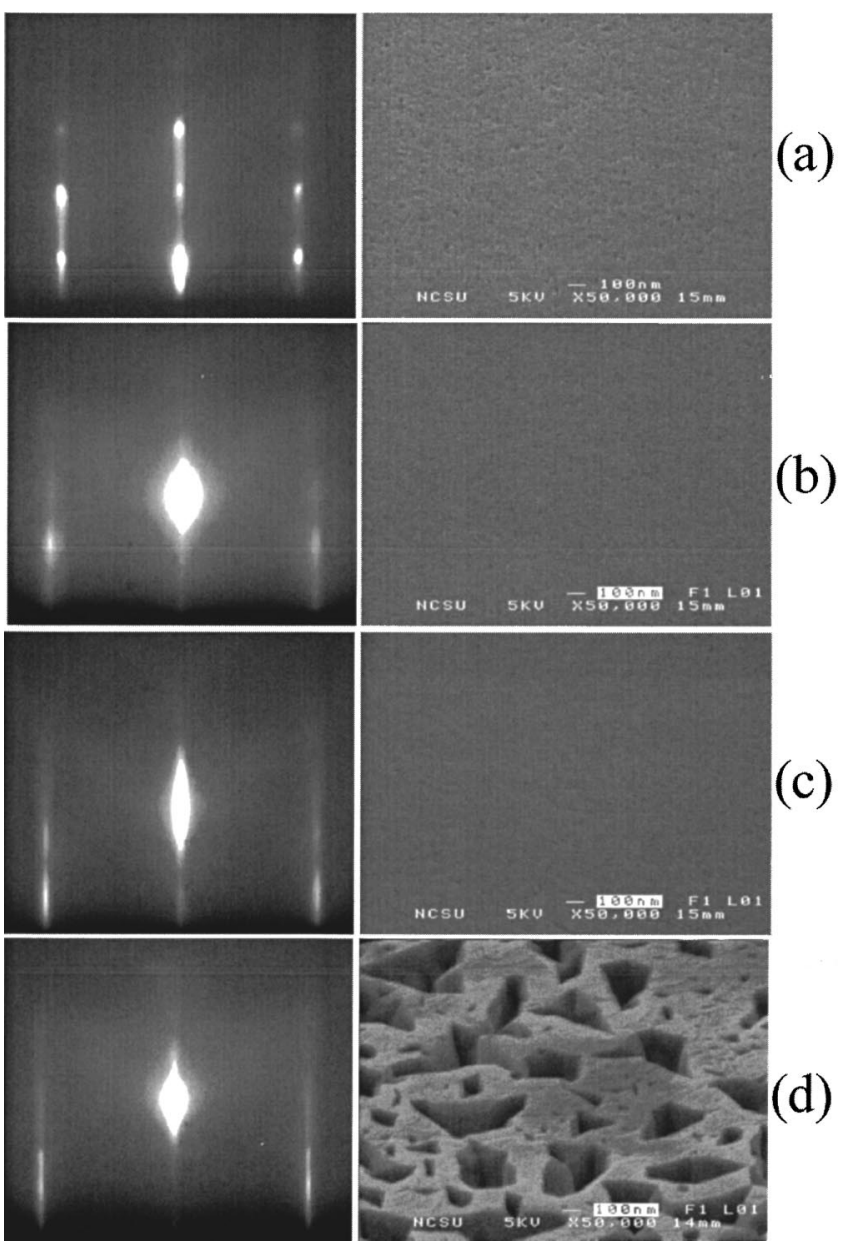

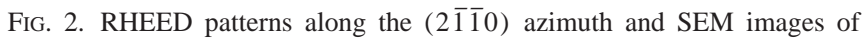
GaN films grown at (a) 700, (b) 730 , (c) 750 , and (d) $780{ }^{\circ} \mathrm{C}$ using 0.55 sccm TEG seeded in He. The $\mathrm{NH}_{3}$ pressures during growth were $1.5 \times 10^{-5}$ Torr, except for (d) $7.7 \times 10^{-6}$ Torr.

$1.5 \times 10^{-5}$ Torr at $730^{\circ} \mathrm{C}$. The apparent activation energies are 0.52 and $0.34 \mathrm{eV}$ for the high- and low-temperature growth regimes, respectively.

RHEED patterns along the $[2 \overline{1} \overline{1} 0]$ azimuth recorded after growth and corresponding $50 \mathrm{k} \times$ top-view SEM images of selected GaN films are displayed in Fig. 2. The films were grown using $0.55 \mathrm{sccm}$ TEG seeded in $\mathrm{He}$ and $1.5 \times 10^{-5}$ Torr $\mathrm{NH}_{3}$, unless otherwise noted. The spotty $1 \times 1$ (transmission) RHEED pattern of the film grown at $700{ }^{\circ} \mathrm{C}$ [Fig. $2(a)]$ indicates a microscopically rough surface, and this asperity is visible in the corresponding SEM image. The surface roughness decreases with increasing substrate temperature up to $750^{\circ} \mathrm{C}$. The streaky $1 \times 1$ RHEED pattern of the film grown at $750^{\circ} \mathrm{C}$ [Fig. 2(c)] corresponds to a smooth featureless surface, as evidenced by SEM. The RHEED pattern of the film grown at $730^{\circ} \mathrm{C}$ [Fig. 2(b)] is transitional with a higher background intensity. The SEM image (not shown) of a film grown at $765^{\circ} \mathrm{C}$ revealed a flat surface with pits approximately $20 \mathrm{~nm}$ in diameter. When the growth temperature was increased to $780^{\circ} \mathrm{C}$, the $\mathrm{GaN}$ surface became faceted and microscopically rough (consistent with a higher effective $\mathrm{N}$ flux). The film morphology at $780^{\circ} \mathrm{C}$ was im- 


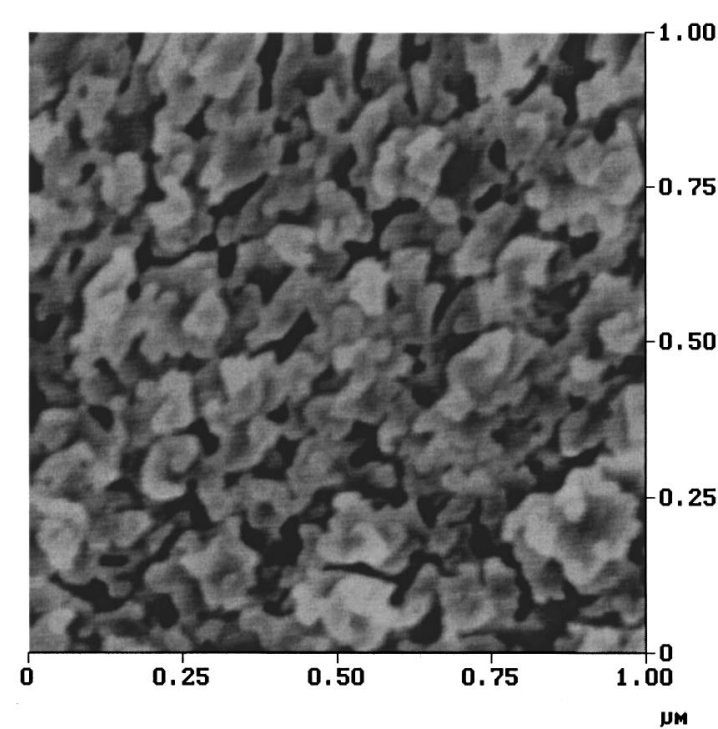

(a)

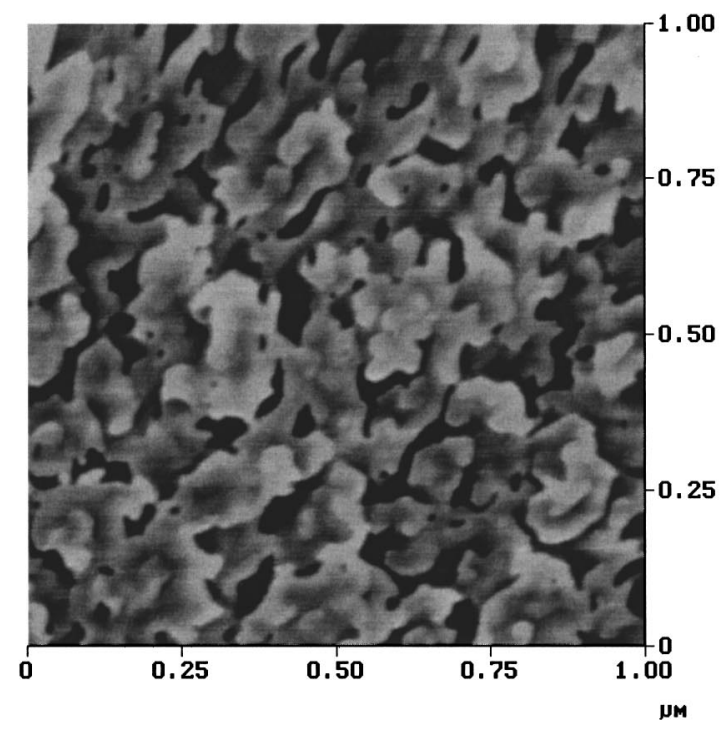

(b)

FIG. 3. AFM images of homoepitaxial GaN films grown at (a) 730 and (b) $750{ }^{\circ} \mathrm{C}$ using $0.55 \mathrm{sccm}$ TEG seeded in $\mathrm{He}$ and an $\mathrm{NH}_{3}$ pressure of 1.5 $\times 10^{-5}$ Torr. The image gray scales are (a) 15 and (b) $10 \mathrm{~nm}$.

proved somewhat by reducing the $\mathrm{NH}_{3}$ pressure from 1.5 $\times 10^{-5}$ to $7.7 \times 10^{-6}$ Torr. The RHEED pattern and SEM image of this film are shown in Fig. 2(d). SEM reveals that the surface is flat, consistent with the streaky RHEED pattern, but there are large irregularly shaped pits in the film. The RHEED data indicate that a transition from threedimensional (3D) to two-dimensional (2D) GaN growth occurs between 730 and $7500^{\circ} \mathrm{C}$.

Ex situ AFM images of GaN films grown at 730 and $750^{\circ} \mathrm{C}$ using $0.55 \mathrm{sccm}$ TEG seeded in $\mathrm{He}$ and $1.5 \times 10^{-5}$ Torr $\mathrm{NH}_{3}$ are shown in Fig. 3. The surface of the film grown at $730{ }^{\circ} \mathrm{C}$ [Fig. 3(a)] is comprised of quasi-2D islands with highly irregular perimeters. Deep crevices are also visible between the islands. The rms roughness calculated for this $1 \times 1 \mu \mathrm{m}^{2}$ image is $1.7 \mathrm{~nm}$, and the image gray scale is 15

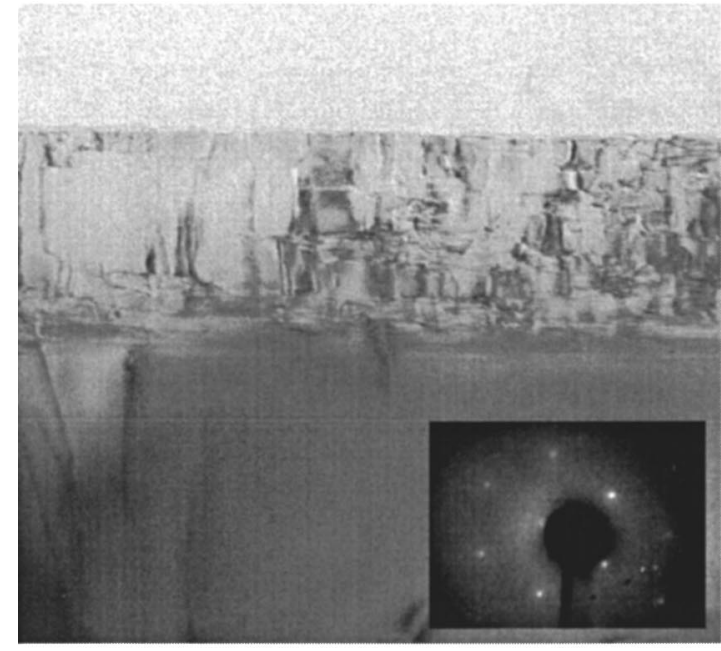

(a)

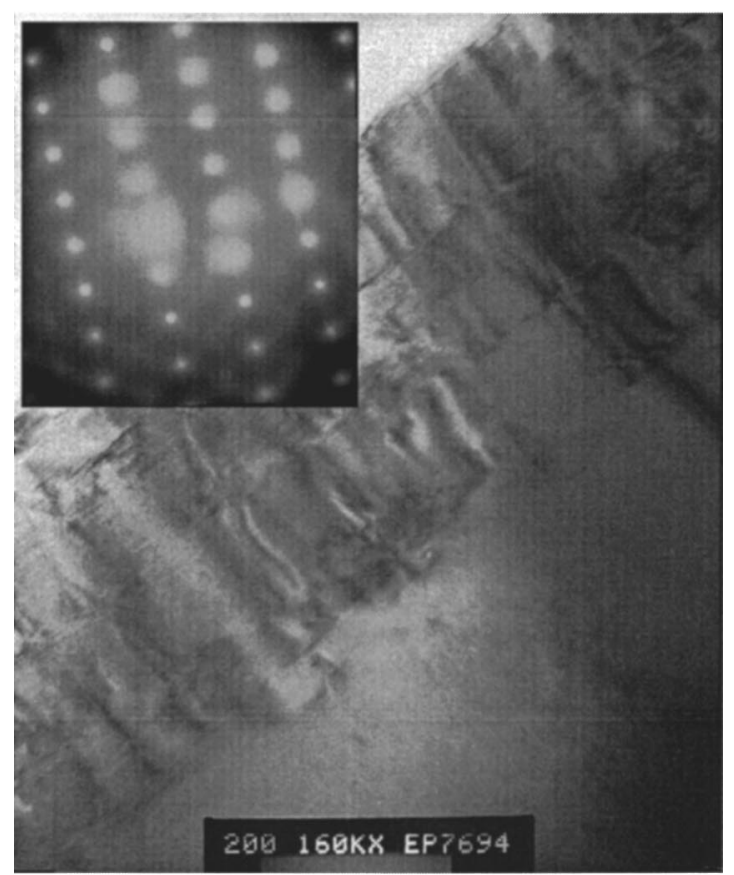

(b)

FIG. 4. (a) Cross-sectional TEM image of a $\mathrm{GaN}$ film grown at $750{ }^{\circ} \mathrm{C}$ (using $0.55 \mathrm{sccm}$ TEG seeded in $\mathrm{He}$ and an $\mathrm{NH}_{3}$ pressure of $1.5 \times 10^{-5}$ Torr) on a MOCVD GaN(0001) substrate. LEED pattern (inset) of the surface recorded at $136 \mathrm{eV}$. (b) Higher magnification TEM image comprising the $\mathrm{GaN}$ film and the substrate, showing the selected area diffraction pattern in the $[2 \overline{1} \overline{1} 0]$ beam direction.

$\mathrm{nm}$. When the growth temperature is increased to $750^{\circ} \mathrm{C}$, the islands become larger, and they appear to be elongated in the direction along the diagonal from the lower left to upper right in Fig. 3(b). AFM line profile analysis indicates that the step height between adjacent islands varies between 2 and 4 $\mathrm{nm}$. The rms roughness calculated for this $1 \times 1 \mu \mathrm{m}^{2}$ image is $1.3 \mathrm{~nm}$, and the image gray scale is $10 \mathrm{~nm}$. We infer that the higher substrate temperature promotes lateral growth and island coalescence.

A cross-sectional TEM image comprising the $250 \mathrm{~nm}$ 
TABLE I. SIMS analysis of GaN films grown using TEG-seeded beams.

\begin{tabular}{|c|c|c|c|c|c|c|c|}
\hline $\begin{array}{l}\text { Substrate } \\
\text { temperature } \\
\left({ }^{\circ} \mathrm{C}\right)\end{array}$ & $\begin{array}{l}\text { TEG flow } \\
\text { rate }(\mathrm{sccm})\end{array}$ & $\begin{array}{c}\mathrm{NH}_{3} \\
\text { pressure } \\
\left(10^{-5} \text { Torr }\right)\end{array}$ & $\begin{array}{c}\text { Carrier } \\
\text { gas }\end{array}$ & $\begin{array}{l}\text { TEG } \\
\text { K.E. } \\
(\mathrm{eV})\end{array}$ & At. \% C & At. $\% \mathrm{O}$ & $\begin{array}{l}\text { Growth } \\
\text { rate } \\
(\mathrm{nm} / \mathrm{h})\end{array}$ \\
\hline 730 & 0.55 & 1.53 & $\mathrm{He}$ & 2.1 & 2.28 & 0.23 & 90 \\
\hline 765 & 0.55 & 1.53 & $\mathrm{He}$ & 2.1 & 0.40 & 0.06 & 71 \\
\hline 750 & 0.41 & 1.53 & $\mathrm{He}$ & 2.2 & 0.57 & 0.08 & 59 \\
\hline 750 & 0.55 & 0.77 & $\mathrm{He}$ & 2.1 & 1.14 & 0.14 & 63 \\
\hline 750 & 0.63 & 0.77 & $\mathrm{~N}_{2}$ & 0.5 & 1.14 & 0.07 & 64 \\
\hline 750 & 0.43 & 0.77 & $\mathrm{~N}_{2}$ & 0.5 & 1.08 & 0.03 & 45 \\
\hline
\end{tabular}

TABLE II. SIMS analysis of GaN films grown at $750{ }^{\circ} \mathrm{C}$ by GSMBE and by SJE using $\mathrm{NH}_{3}$-seeded supersonic beams.

\begin{tabular}{lcccccc}
\hline \hline $\begin{array}{l}\mathrm{NH}_{3} \text { seeding } \\
\text { condition }\end{array}$ & $\begin{array}{c}\mathrm{NH}_{3} \text { flux } \\
\left(10^{15} \mathrm{~cm}^{-2} \mathrm{~s}^{-1}\right)\end{array}$ & $\begin{array}{c}\text { Ga flux } \\
\left(10^{14} \mathrm{~cm}^{-2} \mathrm{~s}^{-1}\right)\end{array}$ & $\begin{array}{l}\mathrm{NH}_{3} \\
\mathrm{K.E.} \\
(\mathrm{eV})\end{array}$ & At. \% C & At. \% O & $\begin{array}{c}\text { Growth } \\
\text { rate } \\
(\mathrm{nm} / \mathrm{h})\end{array}$ \\
\hline $1 \%$ in $\mathrm{H}_{2}$ & 1.26 & 2.95 & 1.48 & 0.006 & 0.007 & 112 \\
$1 \%$ in $\mathrm{H}_{2}$ & 1.26 & 2.95 & 0.74 & 0.007 & 0.006 & 95 \\
$50 \%$ in $\mathrm{N}_{2}$ & 0.63 & 2.95 & 0.13 & 0.003 & 0.004 & 113 \\
$\mathrm{GSMBE}$ & 1.33 & 4.50 & 0.03 & 0.002 & 0.006 & 280 \\
\hline \hline
\end{tabular}

TABLE III. Kinetics data for GaN growth by SJE at $750{ }^{\circ} \mathrm{C}$.

\begin{tabular}{lcccccc}
\hline \hline $\begin{array}{l}\text { Carrier } \\
\text { gas }\end{array}$ & $\begin{array}{c}\text { Carrier flow } \\
\text { rate }(\mathrm{sccm})\end{array}$ & $\begin{array}{c}\text { TEG mole } \\
\text { fraction }(\%)\end{array}$ & $\begin{array}{c}\text { TEG } \\
\text { flow rate } \\
(\mathrm{sccm})\end{array}$ & $\begin{array}{c}\text { TEG } \\
\text { K.E. } \\
(\mathrm{eV})\end{array}$ & $\begin{array}{c}\mathrm{NH}_{3} \\
\text { pressure } \\
\left(10^{-5} \mathrm{Torr}\right)\end{array}$ & $\begin{array}{c}\text { Growth } \\
\text { rate } \\
(\mathrm{nm} / \mathrm{h})\end{array}$ \\
\hline $\mathrm{He}$ & 100 & 0.55 & 0.55 & 2.1 & 1.53 & 64 \\
$\mathrm{He}$ & 100 & 0.41 & 0.41 & 2.2 & 1.53 & 59 \\
$\mathrm{He}$ & 100 & 0.31 & 0.31 & 2.3 & 1.53 & 43 \\
$\mathrm{He}$ & 100 & 0.55 & 0.55 & 2.1 & 0.77 & 63 \\
$\mathrm{He}$ & 100 & 0.41 & 0.41 & 2.2 & 0.77 & 51 \\
$\mathrm{He}$ & 100 & 0.31 & 0.31 & 2.3 & 0.77 & 35 \\
$\mathrm{He}$ & 100 & 0.41 & 0.41 & 2.2 & 0.15 & 41 \\
$\mathrm{He}$ & 100 & 0.31 & 0.31 & 2.3 & 0.15 & 14 \\
$\mathrm{~N}_{2}$ & 50 & 1.26 & 0.63 & 0.5 & 1.53 & 46 \\
$\mathrm{~N}_{2}$ & 50 & 0.86 & 0.43 & 0.5 & 1.53 & 41 \\
$\mathrm{~N}_{2}$ & 50 & 0.70 & 0.35 & 0.5 & 1.53 & 27 \\
$\mathrm{~N}_{2}$ & 50 & 1.26 & 0.63 & 0.5 & 0.77 & 63 \\
$\mathrm{~N}_{2}$ & 50 & 0.86 & 0.43 & 0.5 & 0.77 & 45 \\
$\mathrm{~N}_{2}$ & 50 & 0.70 & 0.35 & 0.5 & 0.77 & 26 \\
$\mathrm{~N}_{2}$ & 50 & 0.70 & 0.35 & 0.5 & 0.15 & 20 \\
\hline \hline
\end{tabular}




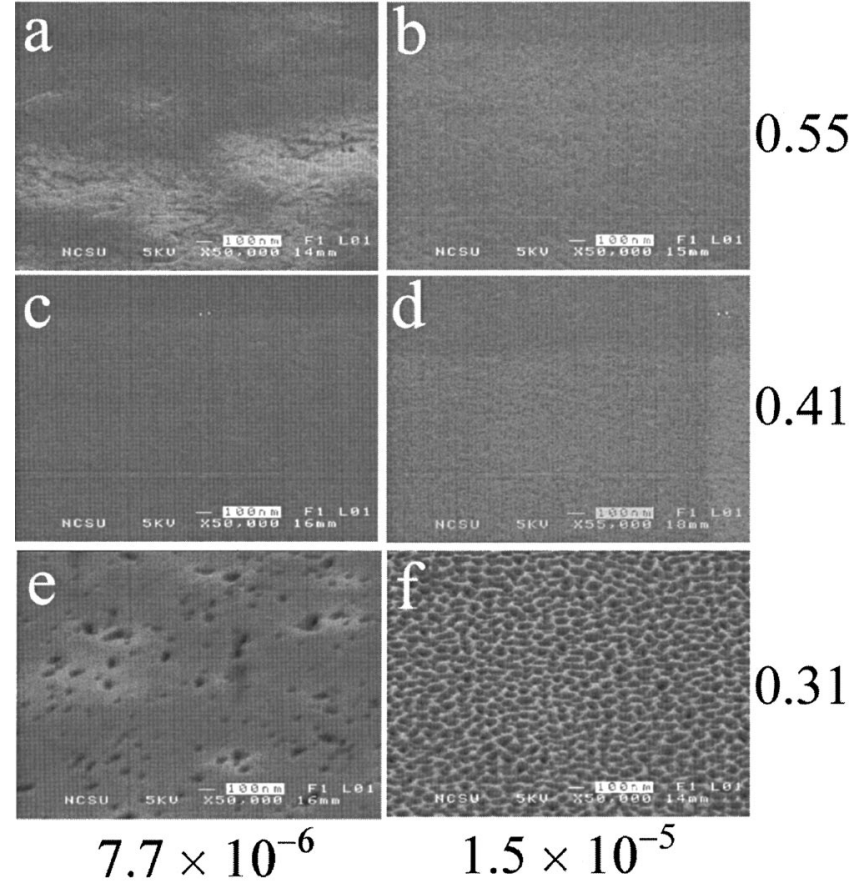

FIG. 5. SEM images of GaN films grown using TEG seeded in He. The TEG flow rates (sccm) and $\mathrm{NH}_{3}$ pressures (Torr) are indicated in the right margin and at the bottom of the figure, respectively.

GaN film grown at $750^{\circ} \mathrm{C}$ and the $\mathrm{GaN}(0001)$ substrate is shown in Fig. 4(a). By comparison, the film contains a high density of planar lattice defects. The inset in Fig. 4(a) shows a $1 \times 1$ low-energy electron diffraction (LEED) pattern of the $\mathrm{GaN}(0001)$ surface. Figure 4(b) shows a higher magnifica-

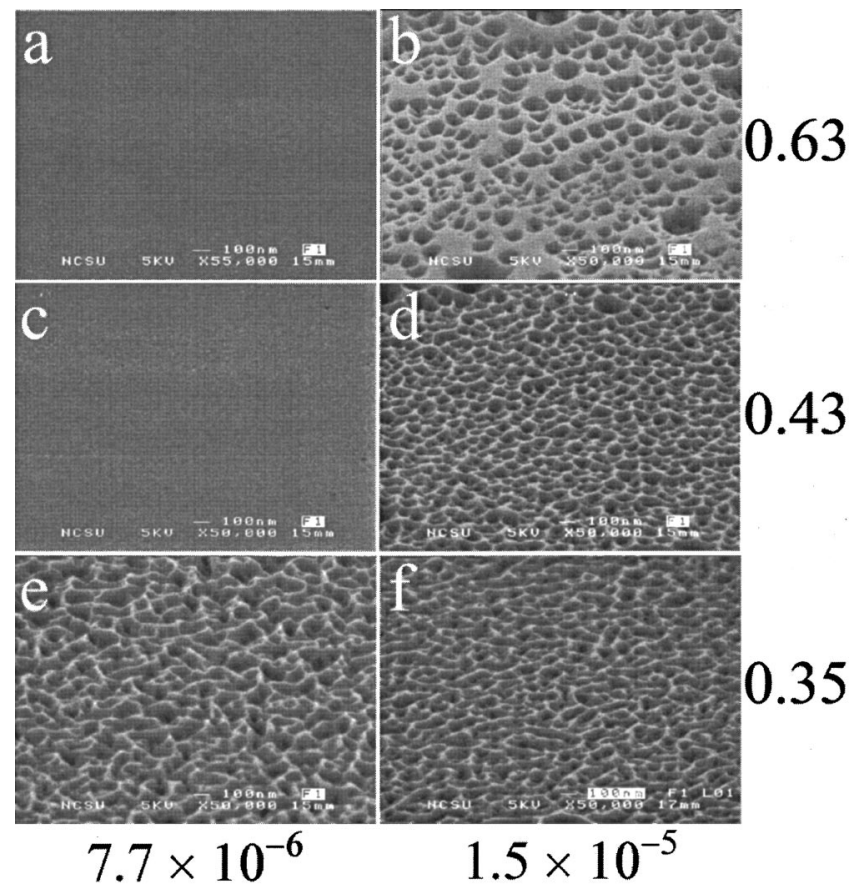

FIG. 6. SEM images of GaN films grown using TEG seeded in $\mathrm{N}_{2}$. The TEG flow rates $(\mathrm{sccm})$ and $\mathrm{NH}_{3}$ pressures (Torr) are indicated in the right margin and at the bottom of the figure, respectively. tion TEM image of the film and substrate; the inset is the corresponding selected area diffraction (SAD) pattern. The SAD pattern contains only one set of diffraction spots in the $[2 \overline{10}]$ beam direction, indicating that the film is homoepitaxial $\alpha-\mathrm{GaN}$.

Substrate temperature and $\mathrm{NH}_{3}$ pressure are the primary factors determining the carbon concentrations in $\mathrm{GaN}$ films grown using TEG-seeded beams. SIMS results for GaN films grown using TEG-seeded supersonic beams are given in Table I. The residual carbon concentrations are high $(0.5-2$ at. \%), and the carbon and oxygen concentrations in the films exhibit some correlation. Increasing the substrate temperature reduces the residual carbon concentration, especially in the $730-750{ }^{\circ} \mathrm{C}$ range. The film grown at $750{ }^{\circ} \mathrm{C}$ exhibits a four-fold reduction in carbon concentration as compared to the film grown at $730{ }^{\circ} \mathrm{C}$ using the same $\mathrm{NH}_{3}$ pressure. A more modest decrease in carbon contamination is observed on increasing the substrate temperature from 750 to $765^{\circ} \mathrm{C}$. Increasing the $\mathrm{NH}_{3}$ pressure from $7.7 \times 10^{-6}$ to $1.5 \times 10^{-5}$ Torr results in a $50 \%$ reduction in carbon contamination in films grown at $750{ }^{\circ} \mathrm{C}$. The small decrease in the TEG flow rate from 0.55 to $0.41 \mathrm{sccm}$ is not believed to have a significant impact on carbon concentrations, based on the data for films grown using low-energy beams of TEG seeded in $\mathrm{N}_{2}$. These data indicate that TEG incident kinetic energy has little effect on the concentrations of contaminants in the films.

SIMS analysis was also performed on films grown at $750{ }^{\circ} \mathrm{C}$ by gas-source MBE (GSMBE) using elemental Ga and $\mathrm{NH}_{3}$ from a variable leak valve and SJE using elemental $\mathrm{Ga}$ and $\mathrm{NH}_{3}$-seeded supersonic beams. ${ }^{22}$ As shown in Table II, the carbon concentrations in these films are two orders of magnitude lower than in the films grown using TEG-seeded beams, and the oxygen concentrations are one order of magnitude lower. The contamination levels in the films grown using $\mathrm{NH}_{3}$-seeded supersonic beams are comparable to those found in the GSMBE film, indicating that effusion of background gases from the differential pumping stages was not a significant source of contamination. We conclude from these results that TEG was the primary source of carbon contamination in GaN films grown using TEG-seeded supersonic molecular beams. The carbon incorporation mechanism may be similar to that reported for GaAs growth using TEG. ${ }^{25}$

The kinetics of GaN growth were investigated at $750{ }^{\circ} \mathrm{C}$ using high- and low-energy supersonic beams of TEG obtained by seeding in $\mathrm{He}$ and $\mathrm{N}_{2}$, respectively. The experimental GaN growth rates are given in Table III. The growth rates exhibit saturation behavior with respect to $\mathrm{NH}_{3}$ pressure and TEG flow rate consistent with LangmuirHinshelwood kinetics. Comparable growth rates were obtained using high- and low-energy beams at an $\mathrm{NH}_{3}$ pressure of $7.7 \times 10^{-6}$ Torr; higher growth rates were obtained using high-energy TEG beams at a $\mathrm{NH}_{3}$ pressure of $1.5 \times 10^{-5}$ Torr.

Top-view SEM images of GaN films grown using highenergy TEG beams are shown in Fig. 5. The surface of the film grown using the highest V/III ratio [Fig. 5(f)] is faceted 


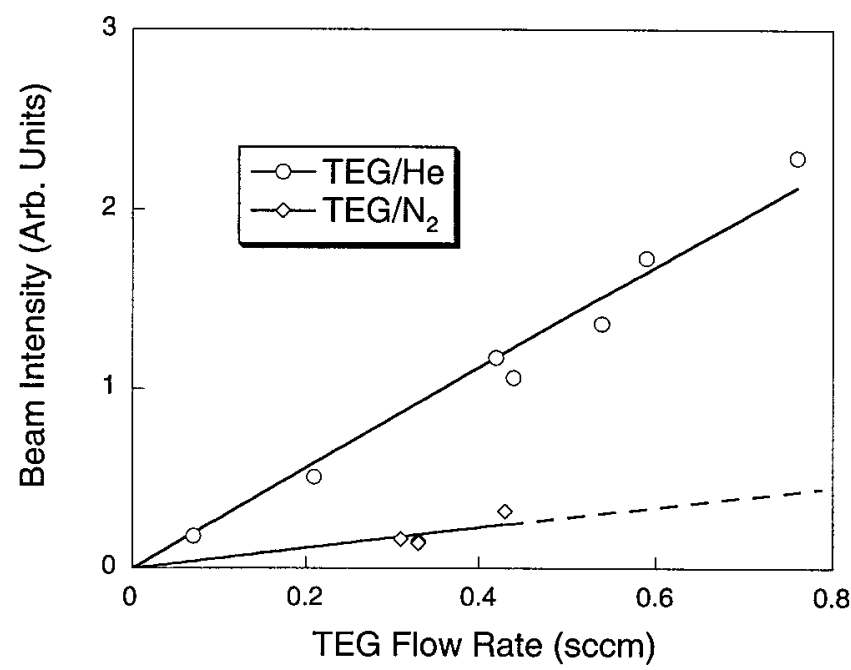

FIG. 7. Relative TEG flux (beam intensity) as a function of TEG flow rate for TEG seeded in $\mathrm{He}$ and $\mathrm{N}_{2}$ supersonic molecular beams.

and microscopically rough. In contrast, films grown using lower V/III ratios are nonfaceted and smooth. The film grown using the lowest V/III ratio [Fig. 5(a)] may be Ga rich, as suggested by the surface contrast in the secondary electron image. A transition from nonfaceted (2D) to faceted (3D) growth with an increase in the $\mathrm{NH}_{3}$ flow rate has been reported for $\mathrm{GaN}$ films grown on AlN-buffered $6 \mathrm{H}-$ $\mathrm{SiC}(0001)$ using TEG and $\mathrm{NH}_{3}$ at $850{ }^{\circ} \mathrm{C} .{ }^{12}$ A similar influence of the V/III flux ratio during growth on the surface morphology of homoepitaxial GaN films grown by plasmaassisted MBE has been reported. ${ }^{26}$ Tarsa et al. and others have suggested that a high nitrogen coverage under $\mathrm{N}$-stable growth conditions limits the $\mathrm{Ga}$ adatom surface diffusion length to less than the mean distance between adjacent bonding sites resulting in "quenched" growth and stochastic roughening of the surface. ${ }^{26,27}$ Top-view SEM images of GaN films grown using low-energy TEG beams are shown in Fig. 6. Most of the films exhibit surface roughness consistent with growth under $\mathrm{N}$-stable conditions. The films tend to become smoother as the V/III ratio is decreased (by either reducing the $\mathrm{NH}_{3}$ pressure or increasing the TEG flow rate), mirroring the trends observed in Fig. 5.

The growth rate enhancement (at $1.5 \times 10^{-5}$ Torr $\mathrm{NH}_{3}$ ) and the improvement in surface morphology of films grown using high-energy TEG beams led us to suspect that a higher TEG flux (beam intensity) was obtained by seeding TEG in He (as compared to $\mathrm{N}_{2}$ ), for equivalent TEG flow rates. To test this hypothesis, TEG beam intensities were measured using a QMS located in the growth chamber. The relative beam intensities are plotted versus TEG flow rate for the high- and low-energy seeded beams in Fig. 7. The data evidence that the TEG beam intensity is higher by about a factor of 5 for the high-energy beams. A likely explanation lies in the different mass separation ("focusing") effects for TEG-He and TEG-N 2 mixtures. Significant differences between the beam flux composition and the source gas composition are typically observed for seeded supersonic molecular beams; the heavier species is focused along the centerline of

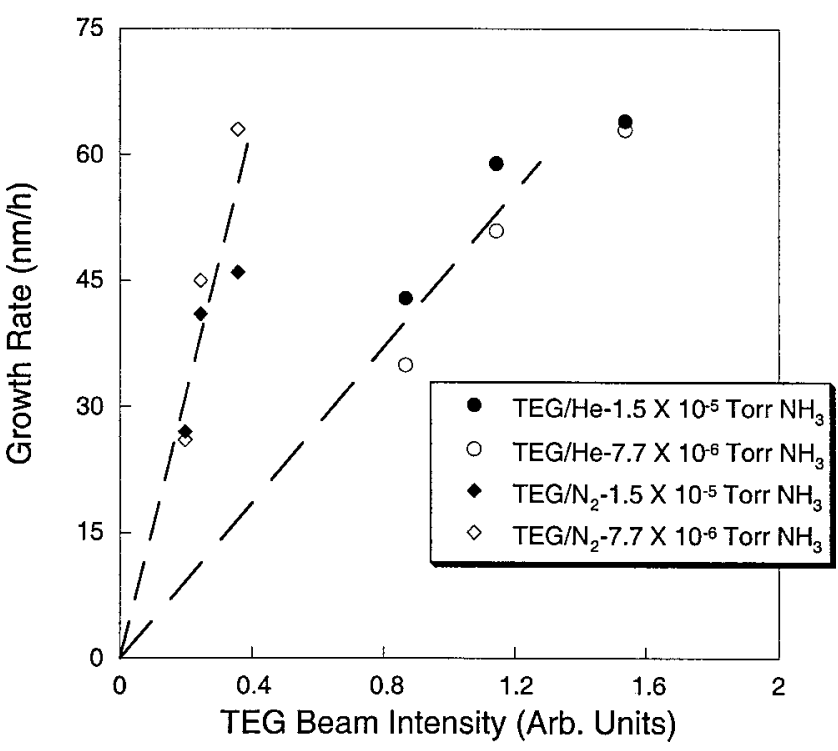

FIG. 8. GaN growth rate versus relative TEG beam intensity for TEG seeded in $\mathrm{He}$ and $\mathrm{N}_{2}$ supersonic molecular beams. Data are included for $\mathrm{NH}_{3}$ pressures of $7.7 \times 10^{-6}$ and $1.5 \times 10^{-5}$ Torr.

the beam while the lighter species is segregated to periphery. ${ }^{24}$ The contributions of pressure diffusion, ${ }^{28}$ Machnumber focusing, ${ }^{29}$ and skimmer interference ${ }^{30}$ to mass separation have been discussed in the literature. The magnitude of the effect is typically a strong function of apparatus parameters, and we have observed significant mass focusing for $\mathrm{NH}_{3}$ seeded in $\mathrm{He}$ and $\mathrm{H}_{2}$ using the current experimental apparatus. $^{22}$

A plot of GaN growth rate versus TEG beam intensity is shown in Fig. 8. The TEG beam intensities were estimated using the linear regression fits shown in Fig. 7. The GaN growth rate exhibits a linear dependence on TEG flux for both low- and high-energy beams under $\mathrm{NH}_{3}$-rich growth conditions. The slopes of the dashed lines through the origin in Fig. 8 are proportional to the Ga incorporation efficiencies for low- and high-energy TEG molecules. Thus, the experimentally determined Ga incorporation efficiency is higher for TEG molecules impinging on the surface at $\sim 0.5 \mathrm{eV}$ than at $\sim 2.1 \mathrm{eV}$ kinetic energy. We infer that the lower Ga incorporation efficiency for high-energy TEG molecules reflects a decrease in the sticking coefficient for dissociative chemisorption. As noted in the introduction, organometallic compounds such as TEG typically undergo precursor-mediated dissociative chemisorption on semiconductor surfaces. ${ }^{21}$ The chemisorption of TEG on GaAs(100) has been studied by several groups using thermal desorption (TPD), ${ }^{31-34}$ molecular beam scattering, ${ }^{26,35-37}$ and high-resolution electron energy-loss spectroscopy. ${ }^{31,38}$ TEG dissociatively chemisorbs on the $\operatorname{GaAs}(100)$ at room temperature. The initial sticking coefficient is nearly unity and drops very sharply to zero at a critical surface coverage consistent with precursor-mediated adsorption. $^{26}$ Lam and Vohs have demonstrated that trimethylgallium (TMG) dissociatively chemisorbs on $\mathrm{GaN}(0001)$ at room temperature. ${ }^{39}$ If the dissociative chemisorption pathway for TEG on $\mathrm{GaN}(0001)$ is also precursor 
mediated, increasing the kinetic energy of TEG molecules should decrease the sticking coefficient.

\section{CONCLUSIONS}

Homoepitaxial GaN films were grown on $\mathrm{GaN}(0001)$ / AlN/6H-SiC composite substrates using TEG-seeded supersonic molecular beams and $\mathrm{NH}_{3}$ from a variable leak valve. A transition from 3D to 2D growth was observed between 730 and $750{ }^{\circ} \mathrm{C}$ for films grown using high-energy TEG beams and a fixed V/III flux ratio. Films grown at $750{ }^{\circ} \mathrm{C}$ under $\mathrm{NH}_{3}$-rich conditions were faceted and microscopically rough; decreasing the V/III flux ratio resulted in 2D growth. SIMS and cross-sectional TEM analysis of selected samples revealed high concentrations $(\sim 1$ at. $\%)$ of carbon (originating from TEG) and high densities of planar lattice defects in the epitaxial layers. A lower Ga incorporation efficiency was found for high-energy supersonic molecular beams of TEG seeded in He. This result is consistent with a decrease in the sticking coefficient for TEG dissociative chemisorption with increasing kinetic energy.

\section{ACKNOWLEDGMENT}

This work was supported by the Office of Naval Research under Contract No. N00014-95-1-0122.

${ }^{1}$ H. Morkoc, S. Strite, G. B. Gao, M. E. Lin, B. Sverdlov, and M. Burns, J. Appl. Phys. 76, 1363 (1994).

${ }^{2}$ R. F. Davis, Proc. IEEE 79, 702 (1991).

${ }^{3}$ J. W. Orton and C. T. Foxton, Rep. Prog. Phys. 61, 1 (1998).

${ }^{4}$ H. Amano, I. Akasaki, T. Kozowa, K. Hiramatsu, N. Sawak, K. Ikeda, and Y. Ishii, J. Lumin. 40-41, 121 (1988).

${ }^{5}$ S. Nakamura, M. Senoh, S. Nagahama, N. Iwasa, T. Yamada, T. Matsushita, H. Kyoku, and Y. Sugimoto, Jpn. J. Appl. Phys., Part 2 35, L74 (1995).

${ }^{6}$ S. Nakamura, Y. Harada, and M. Seno, Appl. Phys. Lett. 58, 2021 (1991).

${ }^{7}$ T. W. Weeks, Jr., M. D. Bremser, K. S. Ailey, E. Carlson, W. G. Perry, and R. F. Davis, Appl. Phys. Lett. 67, 401 (1995).

${ }^{8}$ W. T. Tsang, J. Cryst. Growth 111, 529 (1991).

${ }^{9}$ S. Bharatan, K. S. Jones, C. R. Abernathy, S. J. Pearton, F. Ren, P. Wisk, and J. R. Lothian, J. Vac. Sci. Technol. A 12, 1094 (1994).

${ }^{10}$ C. R. Kingsley, T. J. Whitaker, A. T. S. Wee, R. B. Jackman, and J. S. Foord, Mater. Sci. Eng., B 29, 78 (1995).
${ }^{11}$ E. Kim, I. Berishev, A. Bensaoula, S. Lee, S. S. Perry, K. Waters, and J. A. Schultz, J. Vac. Sci. Technol. B 16, 1270 (1998).

${ }^{12}$ X. Q. Shen, S. Tanaka, S. Iwai, and Y. Aoyagi, J. Cryst. Growth 188, 86 (1998).

${ }^{13}$ B. A. Ferguson and C. B. Mullins, J. Cryst. Growth 178, 134 (1997).

${ }^{14}$ S. T. Ceyer, J. D. Beckerle, M. B. Lee, S. L. Tang, Q. Y. Yang, and M. A. Hines, J. Vac. Sci. Technol. A 5, 501 (1987).

${ }^{15}$ L. Q. Xia, M. E. Jones, N. Maity, and J. R. Engstrom, J. Vac. Sci. Technol. A 13, 2651 (1995), and references therein.

${ }^{16}$ K. A. Pacheco, B. A. Ferguson, C. Li, S. John, S. Banerjee, and C. B. Mullins, Appl. Phys. Lett. 67, 2951 (1995).

${ }^{17}$ K. A. Pacheco, B. A. Ferguson, and C. B. Mullins, J. Vac. Sci. Technol. A 14, 2190 (1997).

${ }^{18}$ S. A. Ustin, K. A. Brown, and W. Ho, Rev. Sci. Instrum. 71, 1479 (2000).

${ }^{19}$ J. J. Sumakeris, R. K. Chilukuri, R. F. Davis, and H. H. Lamb, Mater. Res. Soc. Symp. Proc. 395, 331 (1996).

${ }^{20}$ K. A. Brown, S. A. Ustin, L. Lauhon, and W. Ho, J. Appl. Phys. 79, 7667 (1996).

${ }^{21}$ M. L. Yu and L. A. DeLouise, Surf. Sci. Rep. 19, 285 (1994).

${ }^{22}$ A. J. McGinnis, D. Thomson, R. F. Davis, E. Chen, A. Michel, and H. H. Lamb, Surf. Sci. 494, 28 (2001).

${ }^{23}$ A. J. McGinnis, E. Chen, A. Michel, D. Thomson, R. F. Davis, and H. H. Lamb, J. Cryst. Growth 222, 452 (2001).

${ }^{24}$ D. R. Miller, in Atomic and Molecular Beam Methods, edited by G. Scoles (Oxford University Press, New York, 1988).

${ }^{25}$ N. I. Buchan and M. L. Yu, Surf. Sci. 280, 383 (1993).

${ }^{26}$ E. J. Tarsa, B. Heying, X. H. Wu, P. Fini, S. P. DenBaars, and J. S. Speck, J. Appl. Phys. 82, 5472 (1997).

${ }^{27}$ T. H. Myers, L. S. Hirsch, L. T. Romano, and M. R. Richards-Babb, J. Vac. Sci. Technol. B 16, 2261 (1998).

${ }^{28}$ S. Yamazaki, M. Taki, and Y. Fujitani, J. Chem. Phys. 74, 4476 (1981).

${ }^{29}$ F. S. Sharma, Phys. Fluids 8, 773 (1965).

${ }^{30}$ P. K. Sharma, E. L. Knuth, and W. S. Young, J. Chem. Phys. 64, 4345 (1976).

${ }^{31}$ A. Murrell, A. T. S. Wee, D. H. Fairbrother, N. K. Singh, J. S. Foord, G. J. Davies, and D. A. Andrews, J. Appl. Phys. 68, 4054 (1990).

${ }^{32}$ J. A. McCaulley, V. R. McCrary, and V. M. Donelly, J. Phys. Chem. 93, 1148 (1989)

${ }^{33}$ J. A. McCaulley, R. J. Shul, and V. M. Donnelly, J. Vac. Sci. Technol. A 9, 2872 (1991).

${ }^{34}$ B. A. Banse and J. R. Creighton, Surf. Sci. 257, 221 (1991).

${ }^{35}$ R. Souda and M. L. Yu, Surf. Sci. 280, 115 (1993).

${ }^{36}$ M. L. Yu, U. Memmert, N. I. Buchan, and T. F. Kuech, Mater. Res. Soc. Symp. Proc. 204, 37 (1991).

${ }^{37}$ T. Martin and C. R. Whitehouse, J. Cryst. Growth 105, 57 (1990).

${ }^{38}$ A. Narmann and M. L. Yu, Surf. Sci. 269/270, 1041 (1992).

${ }^{39}$ H. T. Lam and J. M. Vohs, Surf. Sci. 426, 199 (1999). 